\title{
PENGELOLAAN BATUAN REAKTIF (REACTIVE GROUND) DALAM KEGIATAN PELEDAKAN PADA TAMBANG TERBUKA UNTUK PENINGKATAN KESELAMATAN PERTAMBANGAN
}

\author{
Slamet Rachman Jaka ${ }^{1)}$, Agung Wibowo ${ }^{2)}$, Fajerin Dinata ${ }^{3)}$ \\ ${ }^{1)}$ Technical Services Manager, PT. Multi Nitrotama Kimia \\ ${ }^{2)}$ General Manager Business Development \& Technical Support, PT. Multi Nitrotama Kimia \\ ${ }^{3)}$ Drill \& Blast Superintendent, PT. Adaro Indonesia
}

\begin{abstract}
ABSTRAK
PT.Multi Nitrotama Kimia merupakan salahsatu perusahaan jasa pertambangan yang bergerak pada bidang penyedia jasa peledakan dan penjualan bahan peledak terbesar di Indonesia yang bekerjasama dengan banyak perusahaan tambang besar dan terkenal di Indonesia. PT.Adaro Indonesia merupakan salahsatu kostumer dari PT.Multi Nitrotama Kimia yang memiliki indikasi adanya terdapat kondisi batuan reaktif di area operasional penambangannya. Kondisi batuan reaktif ini merupakan suatu kondisi dimana adanya perubahan temperature batuan akibat adanya konten mineral tertentu dalam batuan yang bereaksi dengan Ammonium Nitrate. Jika, kondisi ini tidak diperhatikan, maka berpotensi menimbulkan kondisi tidak aman berupa, peledakan dini. Penelitian dan percobaan dilakukan untuk pemetaan terhadap gambaran kondisi batuan reaktif di beberapa Pit untuk kemudian dimasukkan kepada proses analisa laboratorium untuk mengetahui kondisi reaktif batuan. Uji laboratorium yang dilakukan adalah isothermal test dan mineral content test dengan tujuan mengetahui kondisi reakifitas batuan. Sehingga control dan kelola dalam tindakan preventif bisa dilakukan untuk mencegah terjadinya peledakan dini. Dengan tingkat ketelitian dan akurasi dalam uji laboratorium yang dilakukan terkait kondisi batuan reaktif, lokasi Pit yang memiliki kondisi batuan reaktif bisa teridentifikasi. Pada lokasi Pit yang positif memiliki kondisi batuan reaktif, PT Multi Nitrotama Kimia memberikan tindakan preventif dalam campuran bahan peledak inhibitor dan berhasil membuat kondisi batuan reaktif di PT Adaro Indonesia terkelola dan terkontrol dengan baik.
\end{abstract}

Kata Kunci : Batuan Reaktif, Ammonium Nitrate, Peledakan

\begin{abstract}
PT. Multi Nitrotama Kimia is one of the big mining services company in Indonesia with explosive supply and blasting services as the main business. PT. Adaro Indonesia is one of their customer's with reactive ground potential problem in field situation. Reactive ground is situation were the ground has an exothermic reaction if mixed with Ammonium Nitrate. This situation getting worst to be premature blasting condition if there is no control of that situation. Researches had been develop to do mapping reactive ground situation at the Pits and get sample to do reactive ground laboratory test. These laboratory tests are held to get preventive action for reactive ground control. With high accuracy from laboratory test and sampling process, all of reactive ground spot in operational area been mapped. Every single location with reactive ground situation has a special treatment, which using an inhibitor bulk explosives and successes to control safety issues related reactive ground situation.
\end{abstract}

Keyword : Reactive Ground, Ammonium Nitrate, Blasting 


\section{A. PENDAHULUAN}

\section{A.1. Latar Belakang}

Reactive ground adalah kondisi yang menggambarkan kondisi tanah / batuan dengan banyak kandungan mineral sulfida yang reaktif (terutama : iron \& copper sulphides). Jenis tanah / batuan ini kemudian secara proses kimiawi bereaksi dengan cepat ketika bertemu dengan jenis bulk explosives yang biasa digunakan pada aktivitas peledakan (pertambangan) dimana terjadi peningkatan temperature yang signifikan di dalam lubang. Bahan utama dari jenis bulk explosives ini adalah ammonium nitrate (AN). Reaksi yang terjadi antara AN dengan batuan yang mengandung mineral sulfida merupakan proses auto-katalis dimana setelah beberapa saat mengalami induksi, reaksi akan menuju suatu dekomposisi eksotermis bahkan saat suhu awal campuran kedua reaktan berada pada suhu lingkungan normal.

PT.Multi Nitrotama Kimia merupakan salahsatu perusahaan jasa pertambangan yang bergerak pada bidang penyedia jasa peledakan dan penjualan bahan peledak terbesar di Indonesia, dimana unit usaha ini bekerjasama dengan banyak perusahaan tambang besar dan terkenal di Indonesia. PT.Adaro Indonesia merupakan salahsatu perusahan pertambangan batubara terbesar di Indonesia yang menggunakan jasa PT.Multi Nitrotama Kimia, dimana mereka memiliki area operational penambangan yang berada di Provinsi Kalimantan Selatan. Area Operasional Penambangan perusahaan ini terdiri dari 3 (Tiga) Pit, yaitu : Paringin, Tutupan, dan Wara. Dalam siklus operationalnya perusahaan ini kegiatan peledakan merupakan salahsatu bagiannya, sebagai metoda yang gunakan untuk membantu memberaikan batuan.

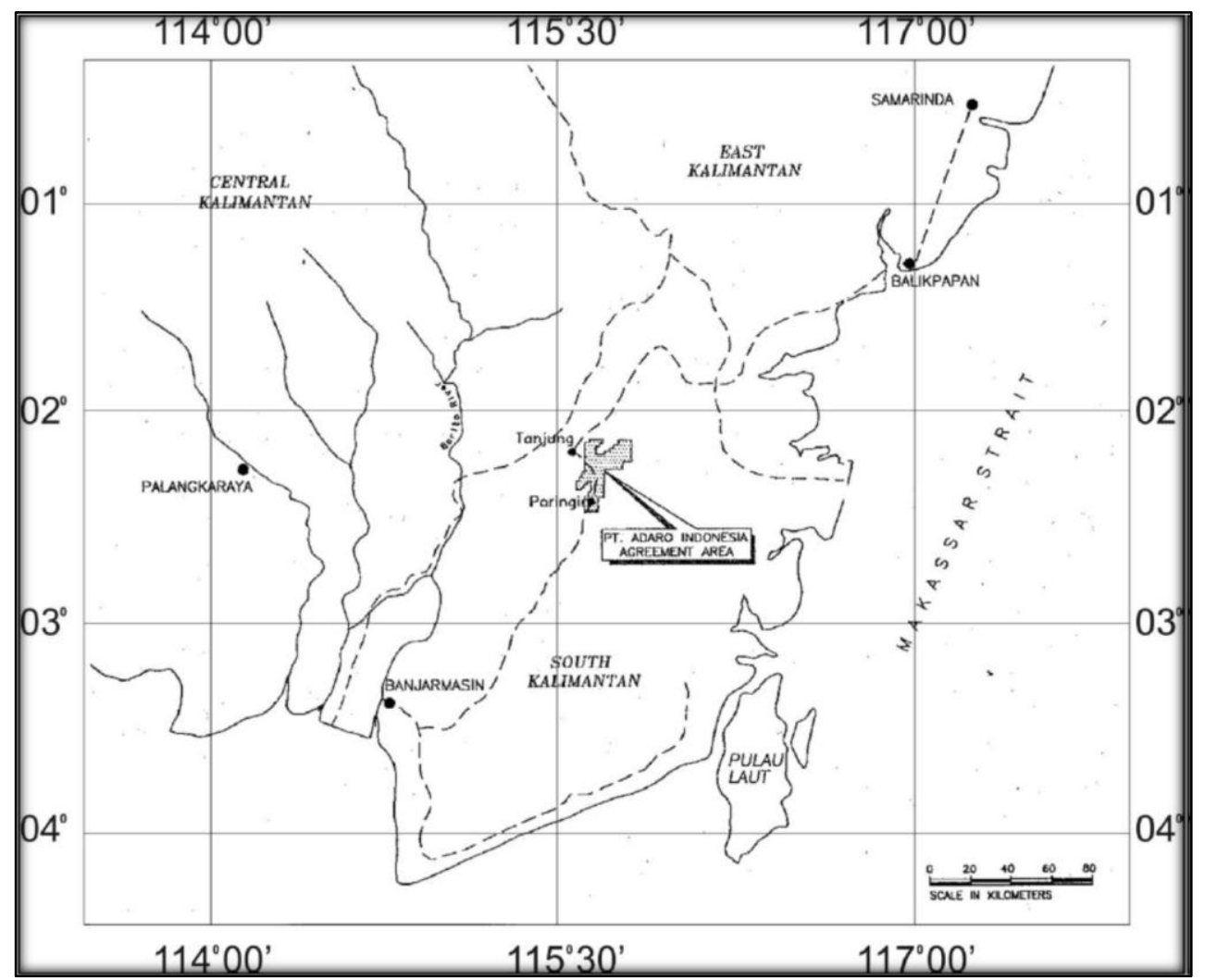

Gambar 1. Area Operasional PT. Adaro Indonesia

\section{A.2. Tujuan Perbaikan}

Reaksi eksotermis pada kondisi reactive ground ketika bertemu dengan bulk explosives berpotensi menimbulkan ledakan dini (premature blasting) dalam suatu lubang ledak. Hal ini tentunya akan mengakibatkan banyak kerugian bagi industri pertambangan. Tahun 2015 terjadi adanya peledakan dini akibat kondisi batuan reaktif di salahsatu tambang batubara terbuka di Indonesia. Masalah ini 
menjadi perhatian PT Adaro Indonesia yang kemudian bekerjasama dengan PT Multi Nitrotama Kimia untuk mengelola isu batuan reaktif ini agar kemudian operasi kegiatan peledakan tetap berjalan dengan aman.

Dari 3 (Tiga) Pit dari PT. Adaro Indonesia dua diantaranya menggunakan peledakan sebagai salahsatu bagian dalam siklus operasional peledakan, yaitu Pit Paringin dan Pit Tutupan. Untuk membuat operasional tambang, terutama kegiatan peledakan tetap aman dan tidak bersinggungan dengan resiko bahaya dari kondisi batuan reaktif (reactive ground) perlu dilakukan tindakan preventive sebagai bagian dari perbaikan berkelanjutan pada prosesnya.

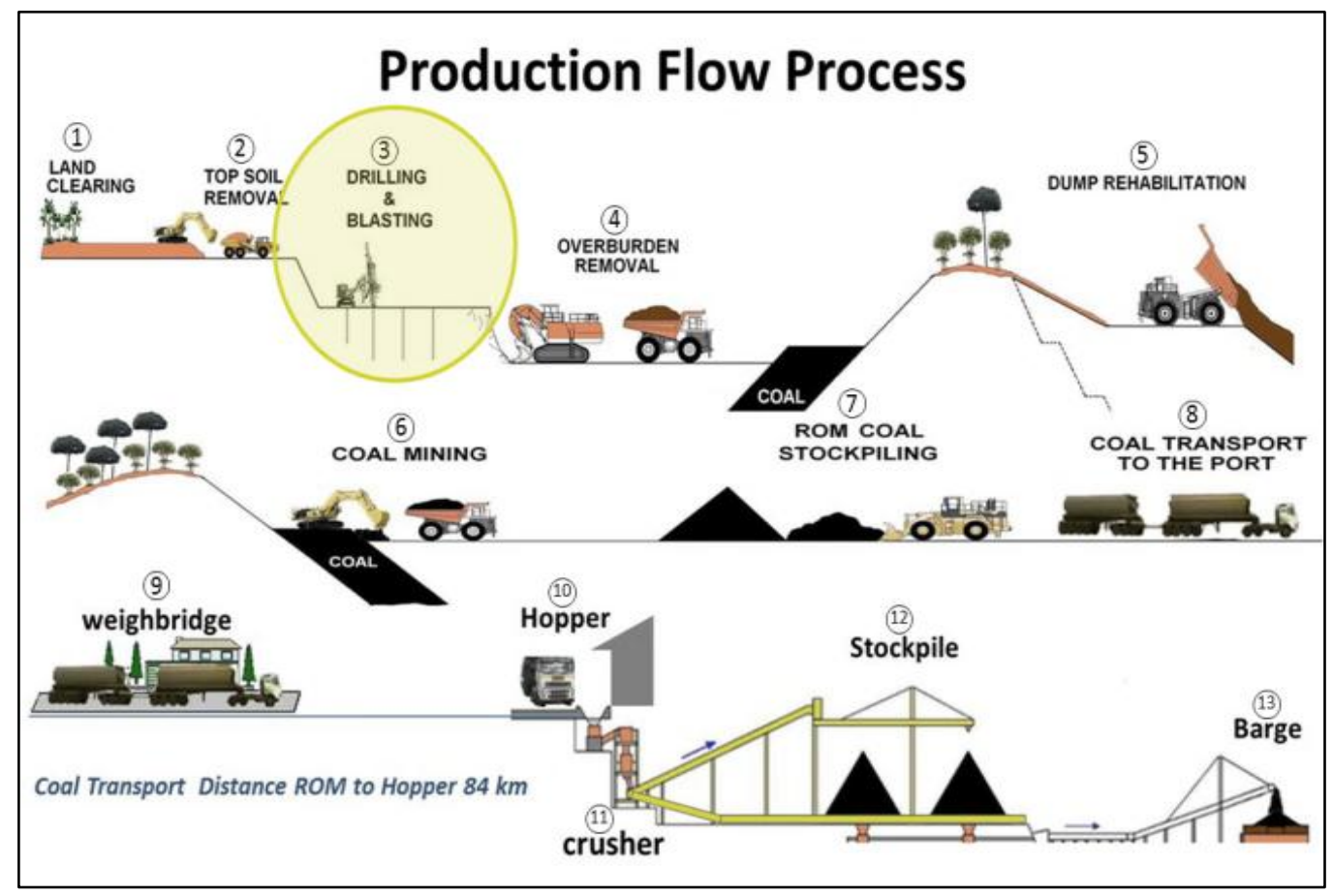

Gambar 2. Siklus Operasional PT. Adaro Indonesia

\section{A.3. Problem Analysis}

Kondisi batuan reaktif memiliki kaitan yang erat dengan unsur mineral sulfide yang terkandung di dalam batuan tersebut. Salah satu ciri indikator keberadaan tanah/batuan in-situ reaktif yang geologi dapat identifikasi yaitu pada keberadaan sulfida (dengan persentasi lebih besar dari 1\%) dan batuan dengan kandungan $\mathrm{PH}<4 \%$. Dengan proses identifikasi ini diharapkan bisa dijadikan dasar dalam tindakan perbaikan selanjutnya.

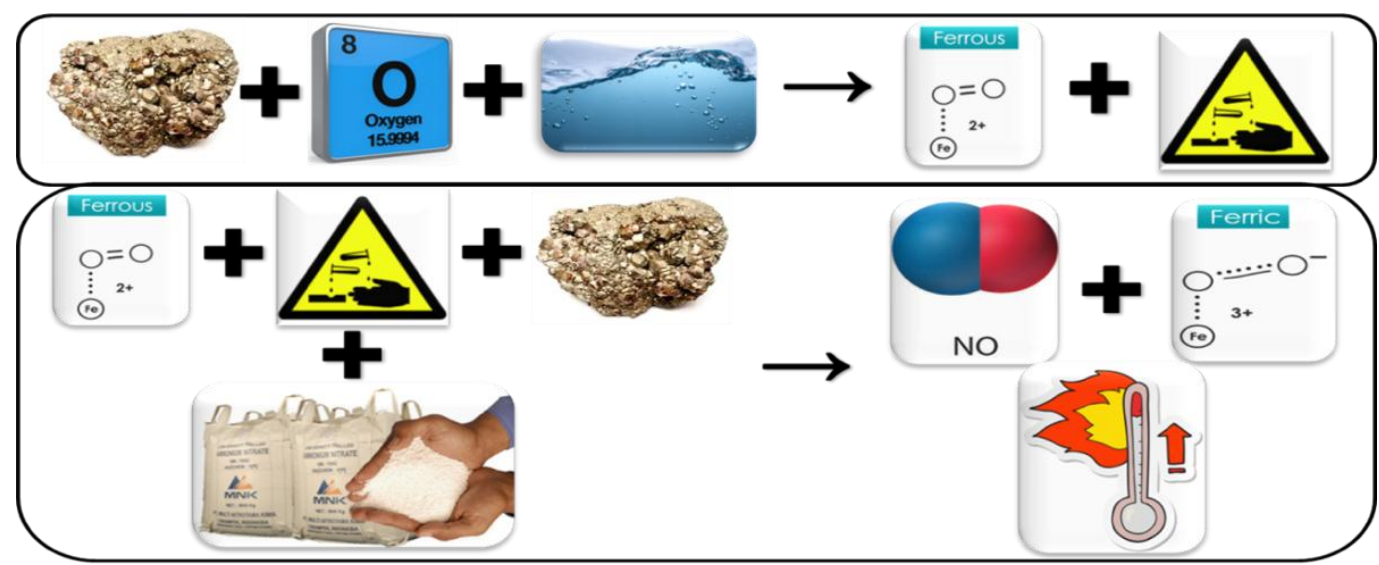

Gambar 3. Reaksi pada kondisi batuan reaktif 


\section{B. PERBAIKAN (IMPROVEMENT)}

\section{B.1. Pemetaan Potensi Batuan Reaktif}

Pada pembahasan sebelumnya, diketahui bahwa kondisi batuan reaktif memiliki asosiasi dengan mineral sulfide. Dalam penelitian ini, penulis bekerjasama dengan Pihak Geologi untuk mengumpulkan data dan melakukan proses pemetaan terhadap area penambangan yang terdapat proses peledakan dalam siklusnya serta yang memiliki unsur mineral sulfide dengan persentase lebih besar dari $1 \%$ dan kandungan $\mathrm{pH}$ kurang dari $4 \%$. Adapun tahapan dalam proses identifikasi dan pemetaan ini antara lain sebagai berikut:

- Identifikasi kepada Pit Tutupan dan Pit Paringin (Pit yang terdapat kegiatan peledakan pada siklus operasionalnya).

- Pit Tutupan dengan karakteristik sesuai target identifikasi berada pada area perlapisan tanah penutup batubara pada seam H Series, G Series, E Series, dan T110-120.

- Pit Paringin dengan karakteristik sesuai target identifikasi berada pada area perlapisan tanah penutup batubara pada seam P812 dan P813.

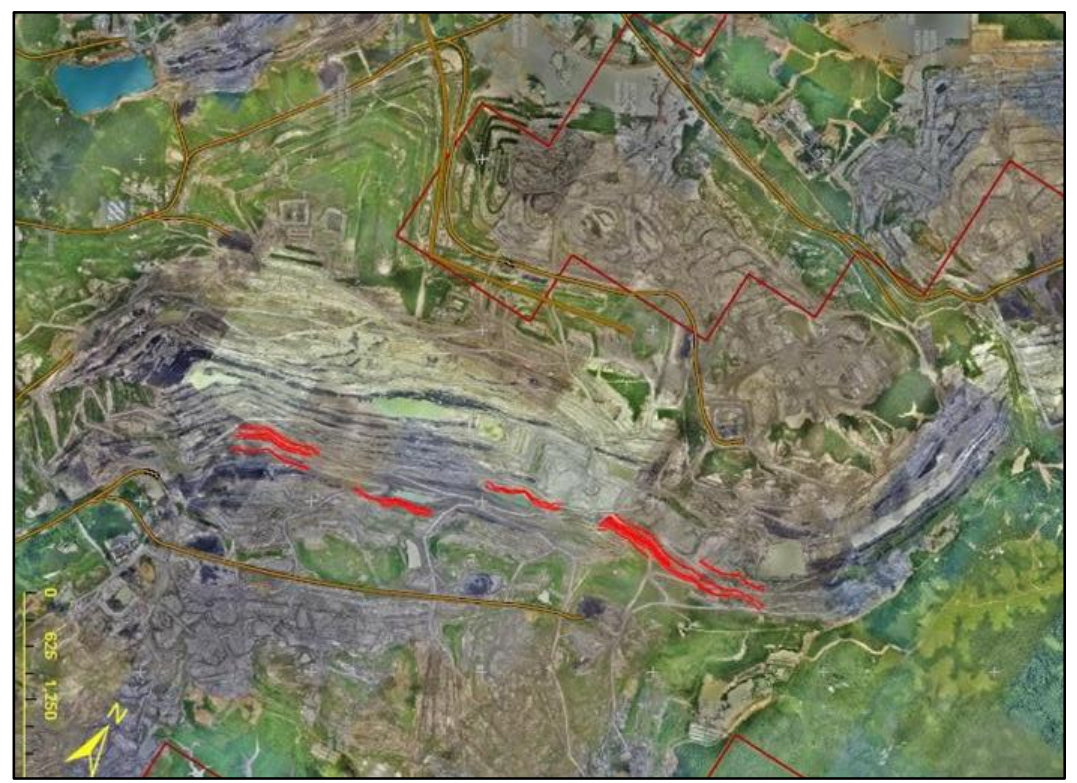

Gambar 4. Area Operasional Pit Tutupan

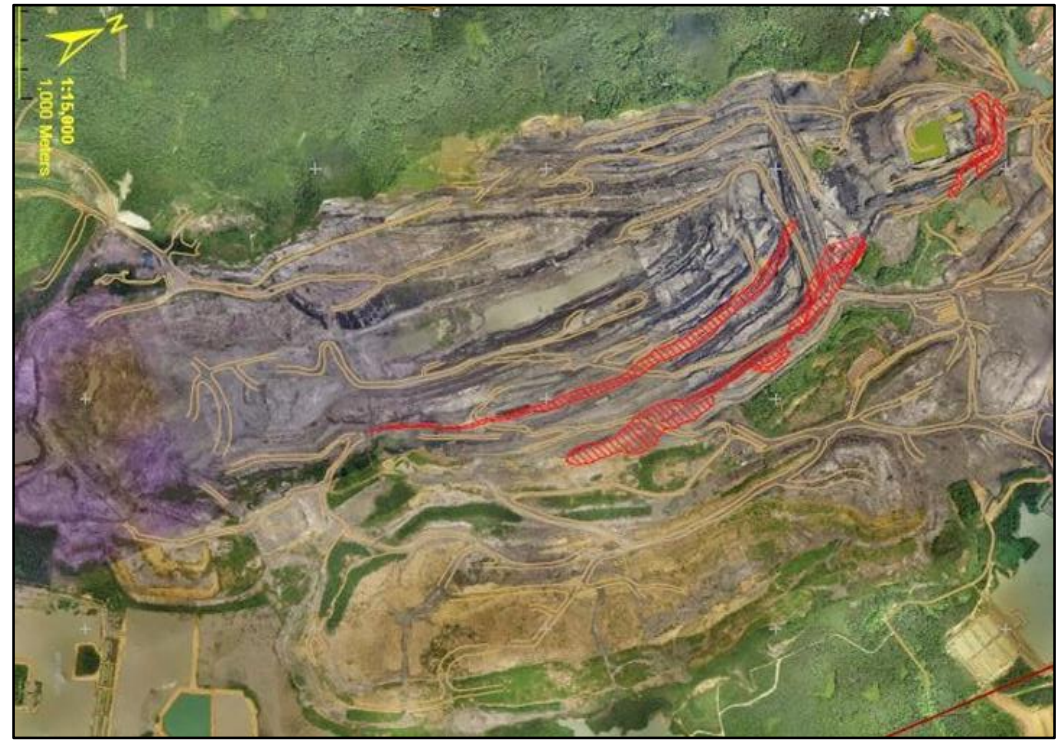

Gambar 5. Area Operasional Pit Paringin 


\section{B.2. Pengambilan Sample Batuan}

Proses pengambilan sample dilakukan mengikuti arahan kriteria yang sudah disepakati bersama dan di bawah pengawasan oleh Tim Geologi. Adapun berat sample yang diambil adalah $2 \mathrm{~kg}$ untuk masing-masing titik. Sample kemudian disimpan pada plastic sample beserta kodenya untuk menghindari kontaminasi dan tertukar dalam proses analisanya nanti. Proses pengambilan dilakukan oleh Team Technical Services PT. Multi Nitrotama Kimia di bawah pengawasan dan arahan Team PT. Adaro Indonesia. Adapun detail berkenaan proses pengambilan sample adalah sebagai berikut:

Tabel 1. Pengambilan Sample Batuan untuk Analisa Reactive Ground

\begin{tabular}{llll}
\hline No. & Kode Sample & Lokasi Pengambilan & Informasi Perlapisan \\
\hline 1 & Sample 1 & Pit Paringin - Highwall & Floor Seam P813 \\
2 & Sample 2 & Pit Paringin - Highwall & Floor Seam P813 \\
3 & Sample 3 & Pit Paringin - Highwall & Roof Seam P812 \\
4 & Sample 4 & Pit Paringin - Highwall & Roof Seam P812 \\
5 & Sample 5 & Pit Paringin - Highwall & Roof Seam P812 \\
6 & Sample 6 & Pit Paringin - Highwall & Roof Seam P812 \\
7 & Sample 7 & Pit Tutupan - South Area & Roof Seam H1 \\
8 & Sample 8 & Pit Tutupan - South Area & Roof Seam H1 \\
9 & Sample 9 & Pit Tutupan - South Area & Roof Seam G \\
10 & Sample 10 & Pit Tutupan - Central Area & Roof Seam E \\
11 & Sample 11 & Pit Tutupan - Central Area & Floor Seam T220 \\
12 & Sample 12 & Pit Tutupan - North Area & Floor Seam T120 \\
13 & Sample 13 & Pit Tutupan - North Area & Floor Seam T110 \\
14 & Sample 14 & Pit Tutupan - North Area & Floor Seam T110 \\
15 & Sample 15 & Pit Tutupan - North Area & Floor Seam T110 \\
16 & Sample 16 & Pit Tutupan - North Area & Floor Seam T120 \\
\hline \multicolumn{2}{l}{ Note $:$ Penamaan Lokasi dan Perlapisan refer kepada Informasi PT. Adaro Indonesia }
\end{tabular}

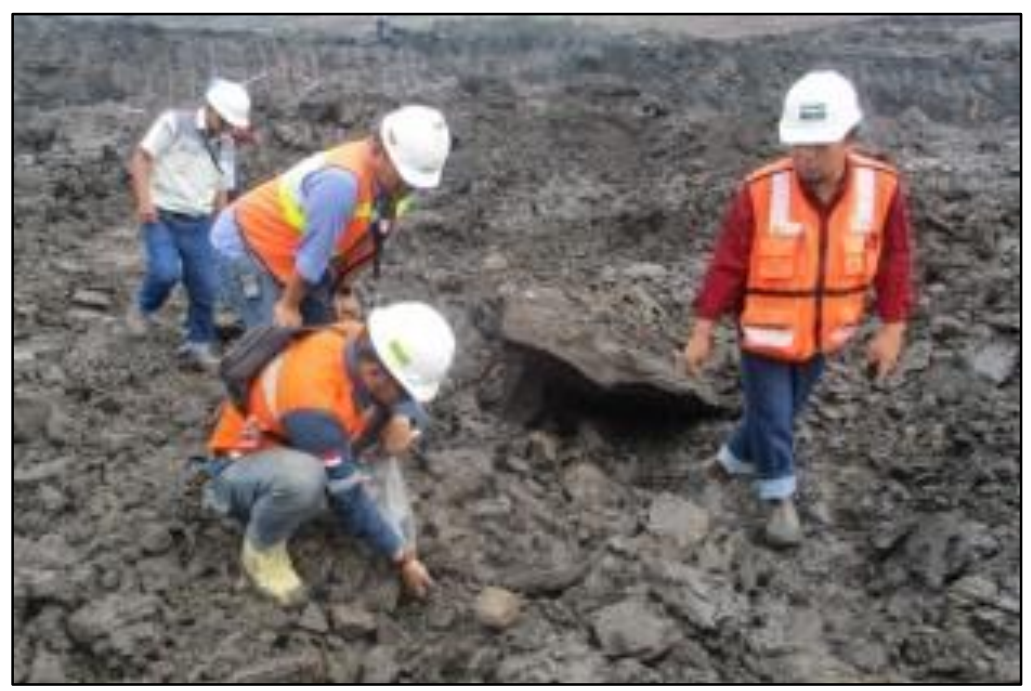

Gambar 6. Proses Pengambilan Sample Batuan

\section{B.3. Analisa Kondisi Batuan Reaktif}

Analisa kondisi batuan reaktif dilakukan di Labaratotium PT. Multi Nitrotama Kimia yang berada di Cikampek, Jawa Barat serta dibawah penanganan analis yang berpengalaman. Proses analisa ini bertujuan untuk mengidentifikasi reaktif ground dan mengetahui efektivitas produk untuk mencegah terjadinya reaksi. Adapun pada proses analisa secara garis besar terbagi menjadi dua bagian, yaitu: 
- Penyaringan reaktivitas; uji ini berguna untuk mengidentifikasi apakah sampel tanah reaktif terhadap ammonium nitrate. Adapun bagian pengujian yang ada pada proses ini antara lain: Uji Tanah Reaktif Isotermal dan Uji Suhu Ramping,

- Pengujian produk; untuk mengidentfikasi apakah produk dapat diterapkan pada reaktivitas tertentu. Adapun bagian pengujian yang ada pada proses ini antara lain: Uji Produk Terpilih, Uji Waktu Inap, dan Uji Produk Inhibitor (Reactive Ground Resistance)

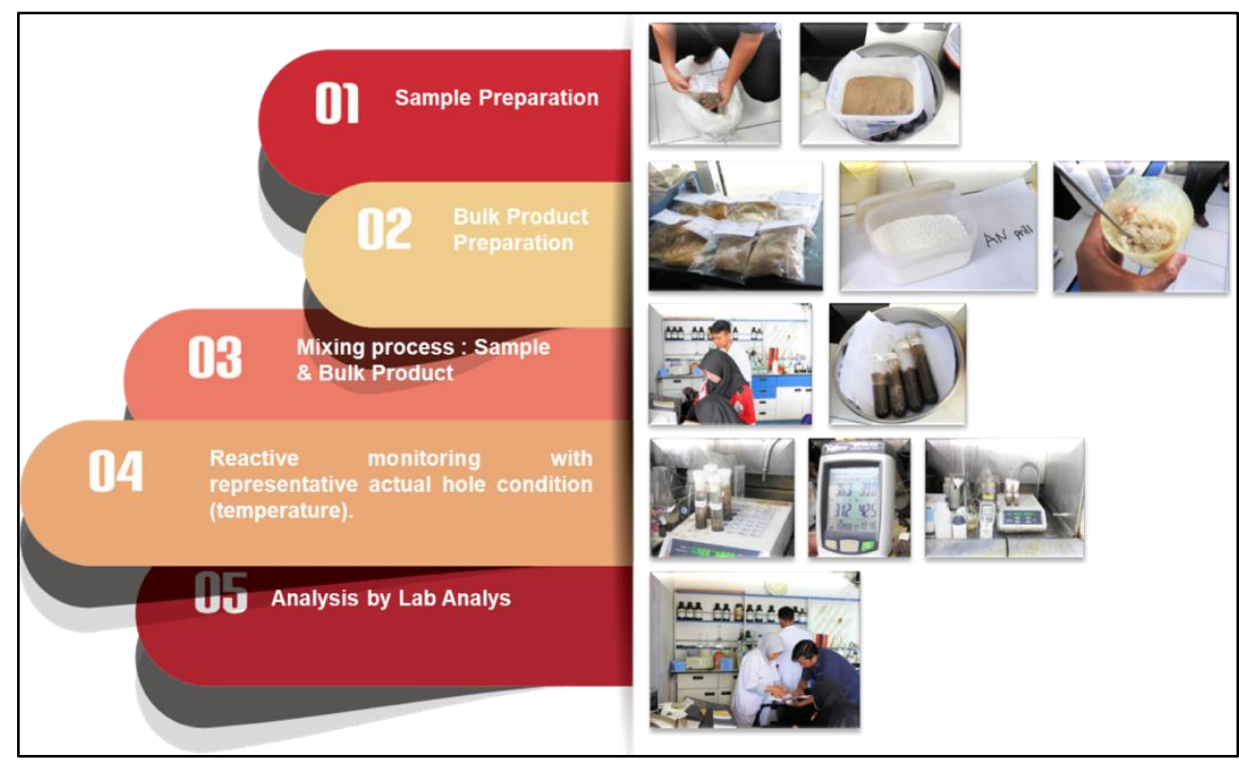

Gambar 7. Bagan Proses Analisa Batuan Reaktif

\section{HASIL \& EVALUASI}

Proses analisa dilakukan dengan penambahan ammonium nitrate pada suhu $55 \mathrm{C}^{0}$ serta pengamatan suhu di set pada datalogger dengan interval 10 menit selama 48 jam. Komponen analisa yang dijadikan referensi dalam penentuan evaluasi antara lain:

- Suhu sampel akan naik minimum $2^{\circ} \mathrm{C}$ dari suhu tetapan awal.

- Menunjukkan kurva positif atau terjadi kenaikan suhu dan akan kembali ke suhu tetapan awal saat reaksi telah selesai.

- Reaksi disertai indikator yang dapat dilihat dengan mudah, seperti munculnya gelembunggelembung atau zat nitrogen oksida yang berwarna cokelat.

- Campuran yang menunjukkan tanda-tanda fisik kereaktifan seperti di atas namun memiliki respon suhu kurang dari $2^{\circ} \mathrm{C}$, dikategorikan sebagai marginal. Marginal dapat diakibatkan jumlah kandungan sulfida pada sampel yang sangat rendah, oksidasi udara yang terjadi terlalu awal pada sampel, atau reaksi yang terjadi bukan merupakan reaksi oksidasi sulfida.

Dari hasil analisa, didapat bahwa terdapat 3 bagian sample yang reaktif terhadap bulk explosives dan berpotensi menimbulkan premature blasting (peledakan dini). Adapun keterangan detail dari sample-sample tersebut adalah:

1) Kode sample 5 dan 6 : Marginal Reaktif. Kedua sample ini diambil dari Pit Paringin bagian Highwall Roof Seam P812.

2) Kode sample 7 : Reaktif. Sample ini diambil dari Pit Tutupan bagian Selatan Roof Seam $\mathrm{H} 1$

Untuk mencegah reaksi peledakan dini (premature blasting) yang berpotensi terjadi pada lokasi yang positif memiliki unsur batuan reaktif, PT. Multi Nitrotama Kimia kemudian menyediakan bahan peledak curah (bulk explosives) yang khusus dengan campuran tertentu yang memungkinkan 
3) Telah dilakukan uji dan analisa terhadap 16 sample yang sudah diambil tersebut di laboratorium PT. Multi Nitrotama Kimia yang berada di Cikampek, Jawa Barat dengan garis besar analisa:

a. Penyaringan reaktivitas; uji ini berguna untuk mengidentifikasi apakah sampel tanah reaktif terhadap ammonium nitrate. Adapun bagian pengujian yang ada pada proses ini antara lain: Uji Tanah Reaktif Isotermal dan Uji Suhu Ramping,

b. Pengujian produk; untuk mengidentfikasi apakah produk dapat diterapkan pada reaktivitas tertentu. Adapun bagian pengujian yang ada pada proses ini antara lain: Uji Produk Terpilih, Uji Waktu Inap, dan Uji Produk Inhibitor (Reactive Ground Resistance)

4) Dari hasil analisa, didapat bahwa terdapat 3 bagian sample yang reaktif terhadap bulk explosives dan berpotensi menimbulkan premature blasting (peledakan dini).

a. Kode sample 5 dan 6 : Marginal Reaktif. Kedua sample ini diambil dari Pit Paringin bagian Highwall Roof Seam P812.

b. Kode sample 7 : Reaktif. Sample ini diambil dari Pit Tutupan bagian Selatan Roof Seam H1

5) Dengan teridentifikasinya kondisi batuan reaktif dan titiknya, kemudian dijadikan referensi dalam proses peledakan di titik tersebut, terutama dalam perencanaan dimana PT. Multi Nitrotama Kimia menyediakan produk bulk explosives yang memiliki daya-tahan terhadap kondisi reaktif.

6) Tindakan preventive yang terangkai dalam proses perbaikan ini sukses menjaga kondisi rekatif yang ada di PT. Adaro Indonesia bisa terjaga dan terkontrol dengan baik.

\section{UCAPAN TERIMA KASIH}

Penulis ingin mengucapkan terima kasih kepada PT.Adaro Indonesia sebagai pelanggan PT.Multi Nitrotama Kimia yang memberikan dukungan dan persetujuan mereka untuk menerbitkan makalah ini.

\section{DAFTAR PUSTAKA}

Anonymous. (2017): Code of Practice Elevated Temperature and Reactive Ground (section 8-9). AEISG. Australia.

Hustrulid. W. (1999): Blasting Principles for Open Pit Mining, Volume 1. (pp. 272-273). Brookfield: A.A. Balkema. Rotterdam. 